\title{
Interleukin-I and cancer progression: the emerging role of interleukin-I receptor antagonist as a novel therapeutic agent in cancer treatment
}

\author{
Anne M Lewis ${ }^{1,2}$, Sheelu Varghese ${ }^{1,3}$, Hui Xu${ }^{1}$ and H Richard Alexander*1,3
}

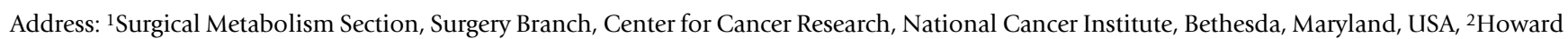
Hughes Medical Institute-National Institutes of Health Research Scholars Program, 4000 Jones Bridge Road, Chevy Chase, Maryland, USA and ${ }^{3}$ Department of Surgery and The Greenebaum Cancer Center, University of Maryland Medical Center, Baltimore, Maryland, USA

Email: Anne M Lewis - anne-lewis@uiowa.edu; Sheelu Varghese - Varghess@mail.nih.gov; Hui Xu - hxu@mail.nih.gov; H Richard Alexander* - HRAlexander@smail.umaryland.edu

* Corresponding author

Published: 10 November 2006

Journal of Translational Medicine 2006, 4:48 doi:10.1 186/1479-5876-4-48
Received: 25 May 2006

Accepted: 10 November 2006

This article is available from: http://www.translational-medicine.com/content/4/I/48

(C) 2006 Lewis et al; licensee BioMed Central Ltd.

This is an Open Access article distributed under the terms of the Creative Commons Attribution License (http://creativecommons.org/licenses/by/2.0), which permits unrestricted use, distribution, and reproduction in any medium, provided the original work is properly cited.

\begin{abstract}
The tumor microenvironment consists of tumor, immune, stromal, and inflammatory cells which produce cytokines, growth factors, and adhesion molecules that promote tumor progression and metastasis. Of particular interest in this setting is interleukin-I (IL-I), a pleiotropic cytokine with numerous roles in both physiological and pathological states. It is known to be up regulated in many tumor types and has been implicated as a factor in tumor progression via the expression of metastatic and angiogenic genes and growth factors. A number of studies have reported that high IL-I concentrations within the tumor microenvironment are associated with a more virulent tumor phenotype. Solid tumors in which IL-I has been shown to be up regulated include breast, colon, lung, head and neck cancers, and melanomas, and patients with IL-I producing tumors have generally bad prognoses. The exact mechanisms by which IL-I promotes tumor growth remain unclear, though the protein is believed to act via induction of pro-metastatic genes such as matrix metalloproteinases and through the stimulation of adjacent cells to produce angiogenic proteins and growth factors such as VEGF, IL-8, IL-6, TNF $\alpha$, and TGF $\beta$. The IL-I receptor antagonist (ILI ra) is a naturally occurring inhibitor to IL-I and acts by binding to the IL-I receptor without activating it. The protein has been shown to decrease tumor growth, angiogenesis, and metastases in murine xenograft models. Our focus in this review is to summarize the known data on the role of IL-I in tumor progression and metastasis and the use of IL-I inhibition as a novel therapeutic approach in the treatment of solid organ malignancies.
\end{abstract}

\section{Background}

The tumor microenvironment consists of tumor, immune, stromal, and inflammatory cells all of which produce cytokines, growth factors, and adhesion molecules that may promote tumor progression and metastases. All intimately interact with one another and play an important role in inflammatory and pro-angiogenic processes and promote tumor cell proliferation. Interestingly, there is an association between chronic inflammation and tumor development or progression; $15 \%$ of all cancers are attributed to inflammatory etiologies [1]. The normal physiologic inflammatory response occurs upon tissue 
injury due to mechanical stimuli, infectious agents, or chemical irritation. Inflammatory cells communicate with fibroblasts and stromal cells via cytokines and chemokines and under the usual circumstances, reparative inflammation is limited. However, chronic pathological inflammation is mediated via the continuing presence of a persistent stimulus, such as tumor cells, and the resulting prolonged inflammatory cytokine exposure has the potential to promote tumor growth through the induction of angiogenesis, DNA damage, and other events favorable to tumor invasion and metastases, as reviewed in reference [2].

Cytokines regulate growth, trafficking, signalling, and differentiation of both stromal and tumor cells. The cytokines produced by cancer cells function to create optimal growth conditions within the tumor microenvironment, while the cytokines secreted by stromal cells may influence the behavior of malignant cells [3]. Cytokines induced by hypoxia, a hallmark feature present in progressive cancers, include vascular endothelial growth factor (VEGF), tumor necrosis factor (TNF), IL-1, and IL-6, as reviewed in reference [2]. TNF is a mediator of acute and chronic inflammation and has been detected in colon, breast, prostate and ovarian carcinomas as well as lymphomas and leukemias [4]. TNF, IL-6, and IL-8 can directly or indirectly promote tumor growth via induction of VEGF expression $[5,6]$. Of particular interest is IL-1, a pleiotropic cytokine with numerous roles in both physiological and pathological states. It is known to be up regulated in many tumor types and has been implicated as a factor in tumor progression via the expression of metastatic and angiogenic genes and growth factors. A number of studies have reported that high IL-1 concentrations within the tumor microenvironment are associated with a more virulent tumor phenotype. The exact mechanism through which IL-1 exerts its proliferative and angiogenic effects is unknown; it is postulated that interactions within the tumor microenvironment are believed an important component.

IL-1 receptor antagonist (IL-1ra) is an approved treatment for patients with rheumatoid arthritis and is being investigated as a potential novel therapeutic in cancer treatment. This naturally occurring protein has been shown to decrease tumor growth, angiogenesis, and metastases in murine xenograft models. There are other agents that are capable of inhibiting the inflammatory and tumor promoting effects of IL-1 such as anti-interleukin-1 monoclonal antibodies, the soluble IL-1 receptor type II, interleukin-1 $\beta$-converting enzyme inhibitors, and IL-1 cytokine traps. Such potential therapeutic agents are currently being applied to the treatment of rheumatoid arthritis, but additional studies are necessary to determine their ability as novel therapy in cancer treatment. Our focus here is on the metastatic and angiogenic properties of IL-1 and the inhibition of this pro-inflammatory cytokine as a novel therapeutic approach in the treatment of solid organ malignancies.

\section{Biochemistry of IL-I}

Three proteins comprise the IL-1 family, two of which are agonists, IL- $1 \alpha$ and IL-1 $\beta$; the third is IL-1 receptor antagonist (IL-1ra). IL-1 $\alpha$ and IL-1 $\beta$ are derived from different genes but are functionally similar, and both bind to the same receptor [7-9]. Although they exhibit similar biological activities, IL- $1 \alpha$ and IL-1 $\beta$ differ in the manner in which they are processed and secreted. IL- $1 \alpha$ is localized in the cytosol or cell membrane and is believed to regulate the intracellular environment $[8,9]$. In contrast, IL-1 $\beta$ is first cleaved by interleukin-1 $\beta$-converting enzyme (ICE) to its mature active form and then secreted extracellularly. Patients with infectious or inflammatory conditions exhibited elevated plasma concentrations of IL- $1 \beta$ but not IL- $1 \alpha$, suggesting the systemic role of IL- $1 \beta[9,10]$.

There are two IL-1 receptors, the biologically active IL- 1 receptor type I (IL-1RI) and the IL-1 receptor type II (IL$1 \mathrm{RII})$. Both are members of the immunoglobulin superfamily and contain structurally similar IL-1 binding sites [8]. IL-1RI is expressed on most cell types, preferentially binds IL- $1 \alpha$, and is responsible for the signal transduction of IL-1, whereas IL-1RII acts as an antagonist. Found within B lymphocytes, neutrophils, and monocytes, IL1 RII preferentially binds IL-1 $\beta$ and contains a shorter cytoplasmic segment. This decreases its signal transduction ability, attenuating the response to IL-1. Due to these antagonistic effects, IL-1RII is referred to as a decoy IL-1 receptor, resulting in its potential as a novel therapeutic agent $[8,11]$. Upon binding of IL-1 to either receptor type, the IL-1R accessory protein (IL-1RAcP) is recruited to the complex [11]. The IL-1RAcP facilitates signal transduction via the recruitment of kinases and activator and intracellular proteins. Without IL-1RAcP, IL-1 remains capable of binding IL-1RI but signal transduction is unable to occur $[11,12]$. This important mechanism affects the efficacy of therapeutics such as IL-1ra that attempt to prevent the IL1 and IL-1RI interaction.

\section{IL-I in cancer}

IL-1 is a pluripotent cytokine responsible for normal physiological roles ranging from the induction of vascular permeability and fever during sepsis to the increased secretion of additional cytokines in autoimmune diseases. Other roles of IL-1 include production and release of prostaglandins, pituitary hormones, and collagenases. IL-1 also stimulates the immune system to boost production of lymphocytes. Therefore, an important balance exists between the beneficial and harmful effects of IL-1. It can negatively impact the vascular, endocrine, connective tis- 
sue, immune, haematopoietic, and central nervous systems, rendering it an important therapeutic target in a number of pathological conditions including rheumatoid arthritis, atherosclerosis, diabetes mellitus type I, inflammatory bowel disease and other autoimmune disorders, Alzheimer's disease, leukaemia, and solid tumors $[8,13,9]$.

Cancer cells directly produce IL-1 or can induce cells within the tumor microenvironment to do so [14]; studies have documented constitutive IL-1 $\beta$ protein production in human and animal cancer cell lines including sarcomas and ovarian and transitional cell carcinomas [9]. Solid tumors in which IL-1 $\beta$ has been shown to be up regulated include breast, colon, lung, head and neck cancers, and melanomas, and patients with IL- $1 \beta$ producing tumors have generally bad prognoses [6,15-17]. Elaraj et al [15] evaluated melanoma, non-small cell carcinoma, colon, and squamous cell cancer cell lines for the gene expression of IL- $1 \alpha$ and IL- $1 \beta$ via real time quantitative reverse transcriptase PCR and found several of these lines to exhibit significantly increased copy numbers of IL- $1 \alpha$ or IL- $1 \beta$ (Table 1). The expression patterns of IL-1 vary; it is expressed in an autocrine or paracrine fashion [18]. IL-1 exhibits autocrine behavior by stimulating the tumor cell itself to invade and proliferate, or it can exert paracrine effects on stromal cells in the microenvironment. The exact mechanisms by which IL-1 promotes tumor growth remain unclear, though the protein is believed to act primarily indirectly (Figure 1). IL-1 induces expression of metastatic genes such as matrix metalloproteinases (MMP) and stimulates nearby cells to produce angiogenic proteins and growth factors such as VEGF, IL-8, IL-6, TNF $\alpha$, and tumor growth factor beta (TGF $\beta$ ) [9,19-21]. Recent studies have determined the necessity of IL-1 in tumor growth, metastasis, and angiogenesis $[7,9]$.

\section{Tumor growth and metastases}

The ability of IL-1 to induce the expression of angiogenic factors such as VEGF and IL- 8 is believed to promote tumor growth and metastasis. Tumor metastasis is a multi-step process requiring numerous factors such as interactions between the tumor cell and its microenvironment $[7,19,22]$. Sawai et al [22] evaluated the role of IL-1 in metastatic and non-metastatic pancreatic cancer cell lines. Metastatic lines demonstrated increased IL-1RI expression compared to non-metastatic lines and exposure to IL- $1 \alpha$ resulted in increased $\alpha 6$ - and $\beta 1$ - integrin subunit expression, whereas IL- $1 \alpha$ exposure in non-metastatic lines had no effect [22]. Additionally, IL-1 $\alpha$ induced adhesion and invasion into laminin in metastatic pancreatic cell lines but not in non-metastatic lines. These studies highlighted the importance of IL- $1 \alpha$ in cell adhesion and invasion into extracellular matrix proteins, and studies by Voronov et al [7] complement findings regarding the importance of IL-1 in metastasis. They demonstrated that IL- $1 \alpha /$ IL-1 $\beta$ knockout mice failed to develop solid tumors following injection of melanoma cells and exhibited significantly improved survival compared to the wildtype animals, which died due to lung metastases [7]. Additional findings established that IL- $1 \beta$ was predominately responsible for the increased metastatic potential of the tumors. These studies indicate that presence of the IL-1RI receptor in cancer cells and IL-1 in the tumor microenvironment are important factors in tumor cell angiogenesis and adhesion and invasion into extracellular matrix $[7,22]$.

\section{Angiogenesis}

The ability of IL-1 to promote tumor proliferation and metastases is mediated via neovascularization $[7,9,15]$; studies suggest the angiogenic effects of IL-1 are indirect $[7,23]$. The indirect effects of IL-1 were illustrated in mouse Lewis lung carcinoma cells by Saijo et al [24]. Cells transduced with IL-1 $\beta$ showed no difference in proliferation rates in vitro but exhibited significantly increased tumor growth rates when injected into mice [24]. Additionally, there were increased microvessels and immunohistochemical staining against the endothelial cell marker, CD31, in transduced xenografts compared with the wild-type and null transfected xenografts. To further elucidate the angiogenic role of IL-1, the study measured concentrations of VEGF, macrophage-inflammatory protein-2 (MIP-2, the mouse homolog to human IL-8), and hepatocyte growth factor (HGF) proteins secreted by IL$1 \beta$-transduced Lewis lung carcinoma cells in vitro. In vitro production of VEGF and MIP-2 was significantly increased, but HGF was increased only in IL-1 $\beta$-transduced xenografts. Such results demonstrate both the importance of the interaction between IL-1 and the tumor microenvironment and the indirect effects of IL-1 [24]. Previous studies in our laboratory [15] further demonstrate the indirect angiogenic properties of IL-1. The supernatant from two melanoma cell lines (PMEL and SMEL) with differential IL-1 expression (low versus high, respectively) was used in an in vitro endothelial cell permeability assay and results demonstrated that only IL-1 producing cell lines (SMEL and non-small-cell carcinoma, H2030) exhibited increased permeability that was inhibited by IL1ra. Increased absorbance indicates increased endothelial cell permeability, an early step in angiogenesis (Figure 2) [15].

A study by Voronov et al [7] demonstrated that IL-1 is essential for angiogenesis and tumor proliferation. They found significantly increased staining for anti-Von Willebrand factor in melanoma cell-containing Matrigel plugs implanted into wild-type mice compared with IL-1 $\beta$ KO mice. Additionally, the angiogenic effects of IL- 1 observed in the wild-type model were restored when IL-1 $\beta$ KO mice 
Table I: Results of IL-I $\alpha$ or IL-I $\beta$ mRNA expression in several tumor cell lines evaluated by quantitative RT-PCR.

\begin{tabular}{lll}
\hline Human tumor cell lines & IL-I $\alpha^{*}$ & IL-I $\beta^{*}$ \\
\hline SMEL (melanoma) & $\mathbf{3 , 2 6 7}$ & 0 \\
WIDR (colon cancer) & 1 & $\mathbf{I 2 2 , 9 3 2}$ \\
H2030 (NSCLC) & 0 & $\mathbf{2 9 , 0 8 4}$ \\
PMEL (melanoma) & 35 & 67 \\
SL-2 (squamous cell cancer) & 140 & 0 \\
\hline
\end{tabular}

* Gene expression is expressed as copy number per $10^{5}$ copies of $\beta$-actin; copy number $>1,000 / 10^{5}$ copies $\beta$-actin is in boldface.

received plug implants containing melanoma cells with IL- $1 \alpha$. These studies found that IL-1 produced within the microenvironment and endogenously produced IL-1 are necessary in the neovascularization of tumors [7].

\section{Anti-tumor activities of IL- I ra}

IL-1ra, the third member of the IL-1 family, is a naturally occurring protein that competitively blocks the IL-1RI on $\mathrm{T}$ lymphocytes and fibroblasts [8]. Due to its ability to block collagenase and prostaglandin synthesis within chondrocytes and synovial cells, IL-1ra (anakinra) is approved for the treatment of rheumatoid arthritis and has been showed as useful in the reversal of IL-1 mediated effects in several pathological settings [8]. IL-1ra prevented severe and lethal hypotension in rabbits administered LPS [25] and attenuated IL-1 mediated intestinal inflammation and necrosis in the immune complexinduced colitis animal model [26]. Additionally, IL-1 ra blocked IL-1 induced production of colony-stimulating growth factors (CSF) by fibroblasts, lymphocytes, and monocytes in acute and chronic myelogenous leukemias [27]. Anakinra is well absorbed in humans, and its safety is well documented with few adverse reactions, making it an ideal candidate in the adjuvant therapy in cancers.

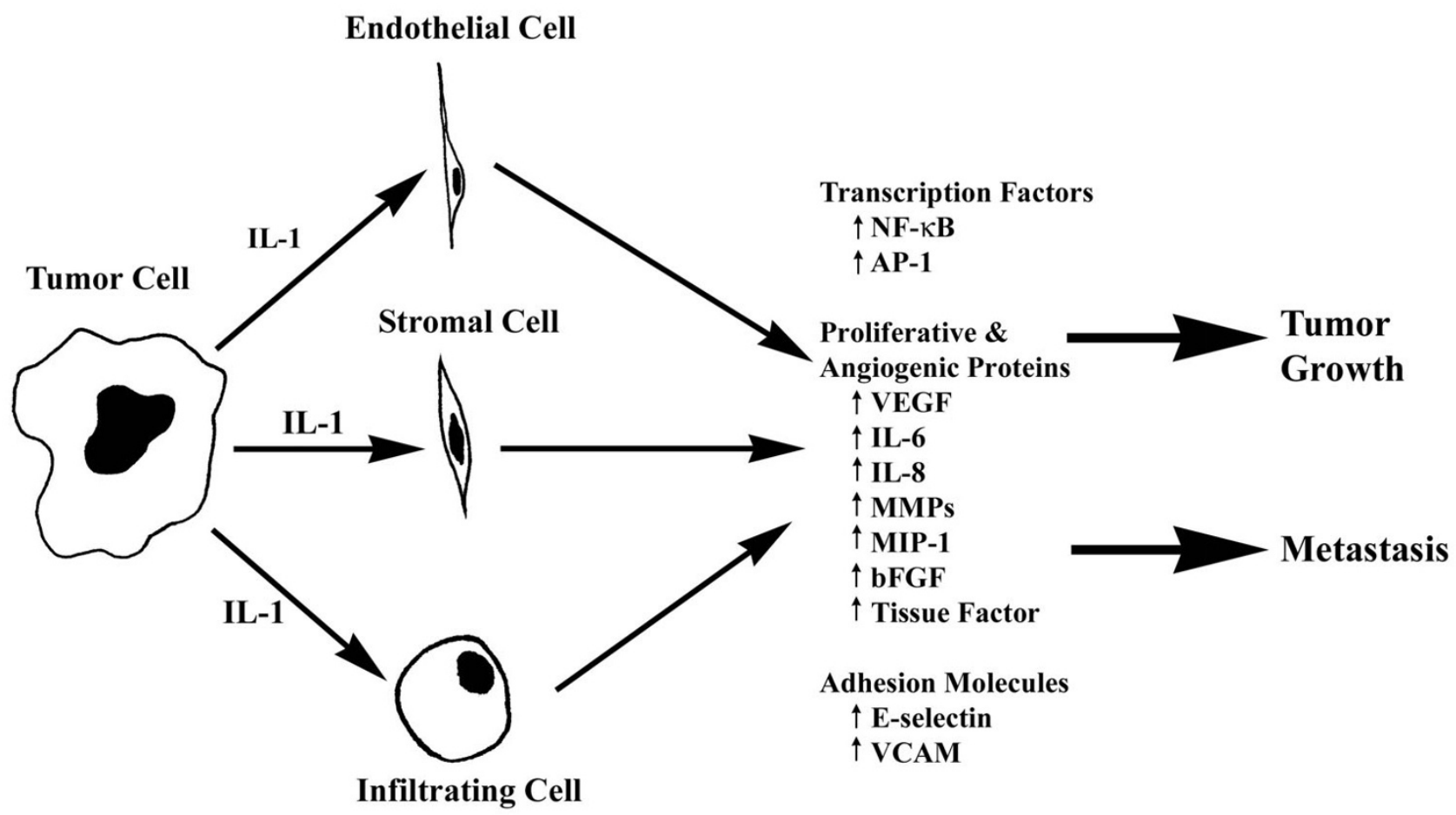

Figure I

Proposed model of how IL-I indirectly alters tumor growth and metastatic potential in vivo. In the tumor microenvironment IL-I has local effects on host infiltrating cells that result in production of proangiogenic and prometastatic mediators. 
A.

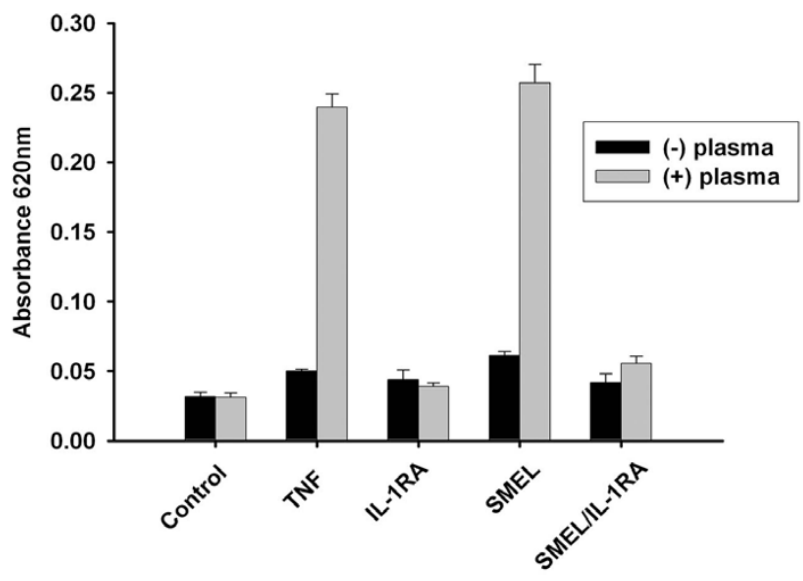

B.

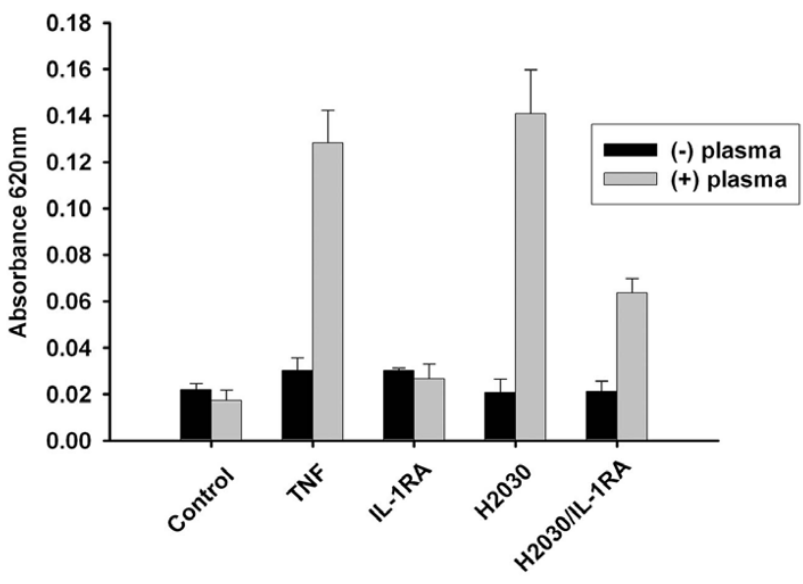

C.

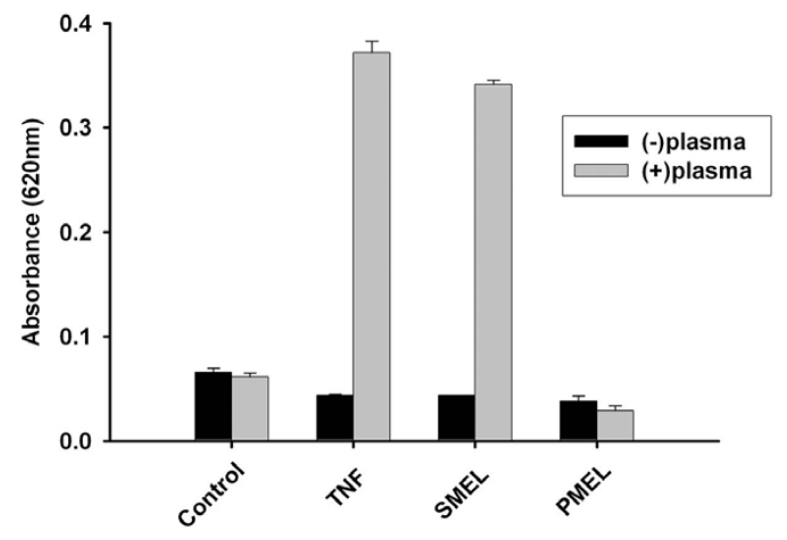

Figure 2

Induction of endothelial cell monolayer permeability by tumor conditioned supernatant in an IL-I-dependent manner. Permeability across functional endothelial cell monolayers was determined by measuring absorbance at $620 \mathrm{~nm}$ I hour following supernatant exposure. Induction of permeability by SMEL (A) and H2030, a lung non-small-cell carcinoma, (B) was completely or partially blocked by co incubation with $10 \mathrm{mg} / \mathrm{mL}$ IL- I Ra. PMEL did not induce permeability under identical experimental conditions (C). Tumor necrosis factor (TNF) at $10 \mathrm{ng} / \mathrm{mL}$ served as positive control. Columns, mean; bars, SE. 
Because IL-1 promotes angiogenesis, tumor growth, and metastases, numerous studies have examined the mechanism and ability of IL-1ra to block such effects. One such study by Konishi et al [19] found that IL-1ra inhibited both in vitro and in vivo Vascular Endothelial Growth Factor production in colon adenocarcinoma cell lines and tumors. They noted an IL-1 $\beta$ dose dependent production of VEGF protein and mRNA expression in cultured colon cancer cell lines. Secretion of the protein was significantly suppressed when the cells were pretreated with IL-1ra. VEGF, IL-1 $\beta$, and IL-1ra concentrations were quantified in tumor samples from patients with colon cancer, and a correlation was observed between the VEGF protein and the IL-1ra: IL-1 $\beta$ ratio within the tumor. Lower ratios of IL1 ra:IL-1 $\beta$ within the tumor correlated with increased concentrations of VEGF protein [19].

Our recent studies focused on the effects of constitutively produced IL-1ra on human melanoma xenografts in a murine model [28]. The specific effects of IL-1ra on tumor proliferation and metastases via the transduction of human IL-1ra into two human melanoma cell lines (PMEL and SMEL) with differential IL-1 $\beta$ expression (low vs. high, respectively) were illustrated. IL-1 ra-transduced, null-transduced, and wild-type cells were grown in vitro. There were no differences in growth rates among the three groups, indicating the lack of direct autocrine effects of IL1 ra on tumor growth. Similarly, ELISA assays confirmed that IL-1ra did not alter the secretion of IL-1 $\beta$ in transduced cells versus the wild-type. IL-1 ra behaved in a paracrine fashion, as illustrated by a mixing study in which wild-type SMEL melanoma cells and SMEL lines transduced with IL-1ra (SMEL/IL-1ra) were mixed in varying ratios ex vivo and then injected into athymic mice. All tested SMEL:SMEL/IL-1 ra ratios resulted in significantly decreased tumor cross-sectional areas, thus demonstrating the paracrine effects of constitutively produced IL-1ra (Figure 3) [28].

The importance of the presence of IL-1 as a tumor growth factor in vivo was also examined. IL-1ra-transduced and wild-type SMEL and PMEL cells were injected subcutaneously into nude mice, and only tumors which constitutively produced IL-1 $\beta$ (SMEL) were affected by IL-1ra transduction. There was significantly decreased tumor growth between the SMEL/IL-1ra and the null-transduced and wild-types, whereas there was no difference in the low IL-1 $\beta$ secreting line [28]. Additionally, SMEL/IL-1ra tumors exhibited massive necrosis within the center of the tumor which was not present in wild-type tumors, and pulmonary metastases in the SMEL/IL-1 ra group were significantly fewer than in the null-transduced and wild-type groups (Figure 4) [28].
Another study evaluated the mechanism and effects of systemically administered IL-1ra on established human tumors in a murine model. Human cancer xenografts in mice receiving systemic IL-1ra administration showed decreased tumor growth and metastases only when the tumor secreted significant concentrations of IL-1 $\beta$. Histologically, we failed to note any significant differences in mitotic rate between control and IL-1ra treated tumors obtained from mice. This coupled with in vitro experiments that also failed to demonstrate alteration in proliferation rates between IL-1ra treated and control cells, emphasizes the indirect role of IL-1 and the importance of its interaction between the tumor and microenvironment. This indirect role was further examined in experiments investigating the effect of IL-1ra on gene expression of IL8. Iinterleukin-8, an angiogenic cytokine induced by IL-1, acts on endothelial cells to promote chemotaxis, cell retraction, and gap formation $[8,29]$. The results demonstrated that although IL-1ra treatment decreased IL-8 mRNA expression and protein concentration in IL-1ra sensitive xenografts, it had no effect in vitro [15]. Therefore, it is likely that the mechanism by which IL-1ra exerts its effects is through the tumor microenvironment rather than through direct blockade of the IL-1RI [15].

Multiple studies have investigated the necessity of IL-1 in tumor growth, metastases, and angiogenesis, which has resulted in the investigation of IL-1 ra as a novel therapeutic agent in solid tumors constitutively producing IL-1. Such studies have found that IL-1ra decreases metastases and tumor proliferation in vivo, as well as decreasing the gene expression and production of angiogenic proteins such as VEGF and IL-8. A summary of the demonstrated anti-tumor activities of IL-1 blocking therapies is reviewed in Table 2. Based on these data, IL-1 ra may prove clinically relevant in the treatment of certain cancers when used either alone or in conjunction with other chemotherapeutics.

\section{Novel therapeutic anti-IL-I agents}

Despite numerous studies citing the safety and potential beneficiary effects of IL-1ra, there exist questions regarding its efficiency in long term treatment of diseases such as cancer. Although anakinra has proven successful in the treatment of rheumatoid arthritis in select patients, large doses are required daily to elicit responses. IL-1 receptors are regenerated rapidly and with the exception of red blood cells, are ubiquitously expressed throughout the body. This, combined with IL-1ra's short half-life (4-6 h) presents formidable challenges to the therapeutic potential of this compound in cancer treatment. For IL-1ra to completely neutralize the tumor proliferating, angiogenic, and metastatic effects of IL-1, sustained concentrations are necessary to saturate all IL-1 receptors. Recent studies $[15,28]$ support this hypothesis. In mice treated with IL- 


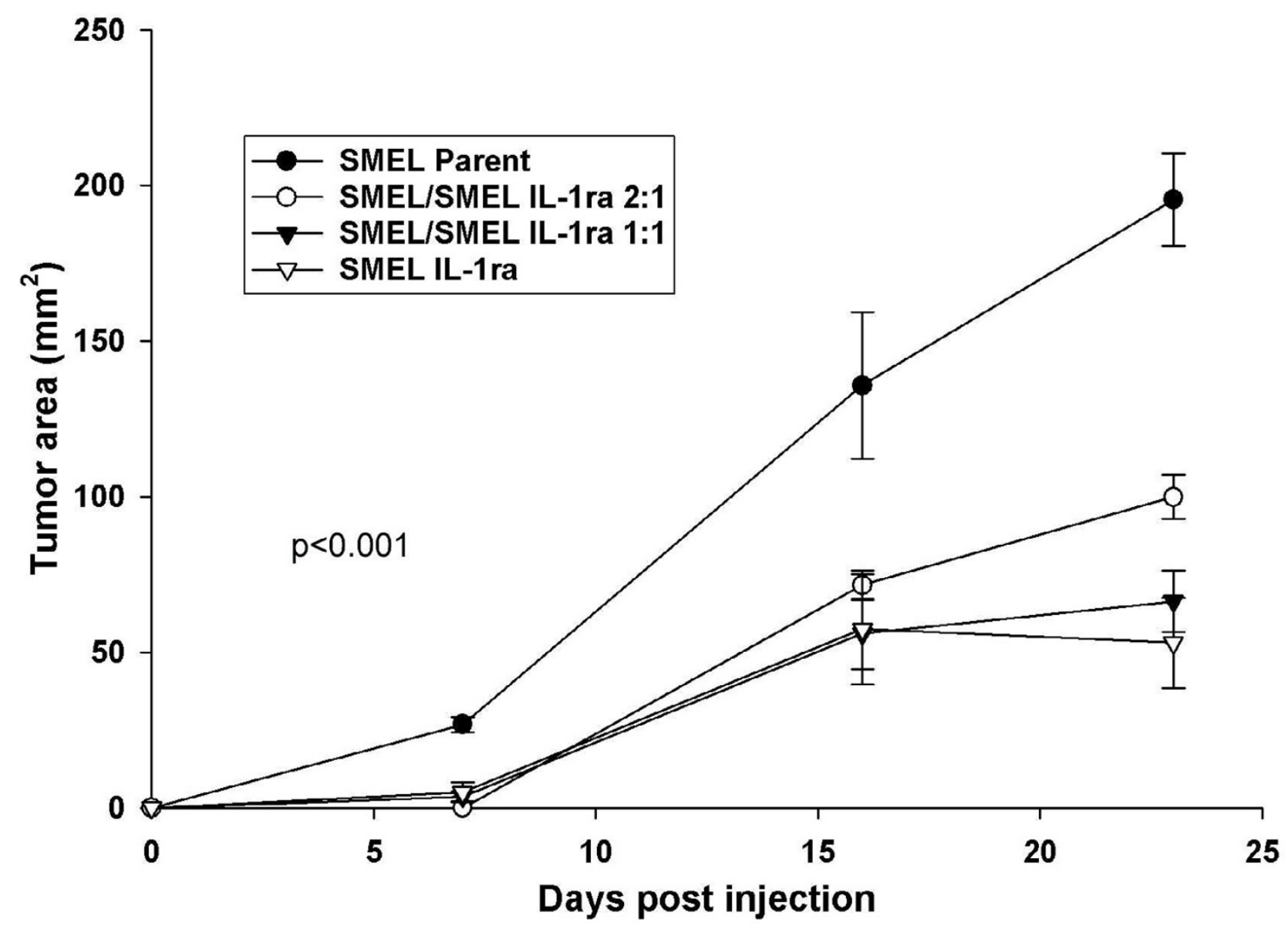

Figure 3

Anti-tumor activity of IL-I ra gene transduction and over-expression in melanoma xenografts. An IL-I producing melanoma (SMEL) was mixed at the indicated ratios with the same cell line that was transduced to over-express IL-I ra (SMEL/ $\mathrm{IL}-\mathrm{Ira}$ ) ex vivo and injected s.c. into athymic nude mice. There was significant growth inhibition at all tested ratios, indicating a marked paracrine effect of IL-I ra on tumor growth.

1ra, only partial xenograft inhibition was observed, whereas IL-1ra-transduced xenografts demonstrated near complete growth inhibition (Figures 3 \&5) [15,28]. Thus, although IL-1ra has demonstrated some benefit as a cancer therapeutic, many other novel therapies remain under investigation.

\section{Anti-interleukin-I monoclonal antibodies}

Therapies using antibodies to IL-1 $\beta$ have been investigated by Neidhart et al. IL-1ra and anit-IL-1 $\beta$ monoclonal antibodies tested individually on a human rheumatoid arthritis cartilaginous matrix model decreased cartilaginous destruction by $45 \%$ and $35 \%$, respectively [30]. Additionally, CDP-484 (Celltech), a pegylated IL-1 $\beta$ antibody, has demonstrated inhibitory IL-1 $\beta$ activities as measured by decreased neutrophil accumulation, as reviewed by Braddock et al [31]. In their review, Braddock et al report an in vivo study in which mice with collageninduced arthritis were either treated with prophylactic pegylated IL-1 $\beta$ antibody or vehicle. Only $20 \%$ of members of the prophylactic group developed collageninduced arthritis, whereas $90 \%$ of the control group developed the disease [31].

\section{Soluble IL-IRII}

As mentioned previously, the IL-1 type II receptor (IL1 RII) behaves as a decoy receptor due to its lack of the cytoplasmic domain necessary for signal transduction. It therefore behaves as an inhibitor of IL-1 activity. IL-1RII occurs in membrane bound and soluble forms; the solu- 


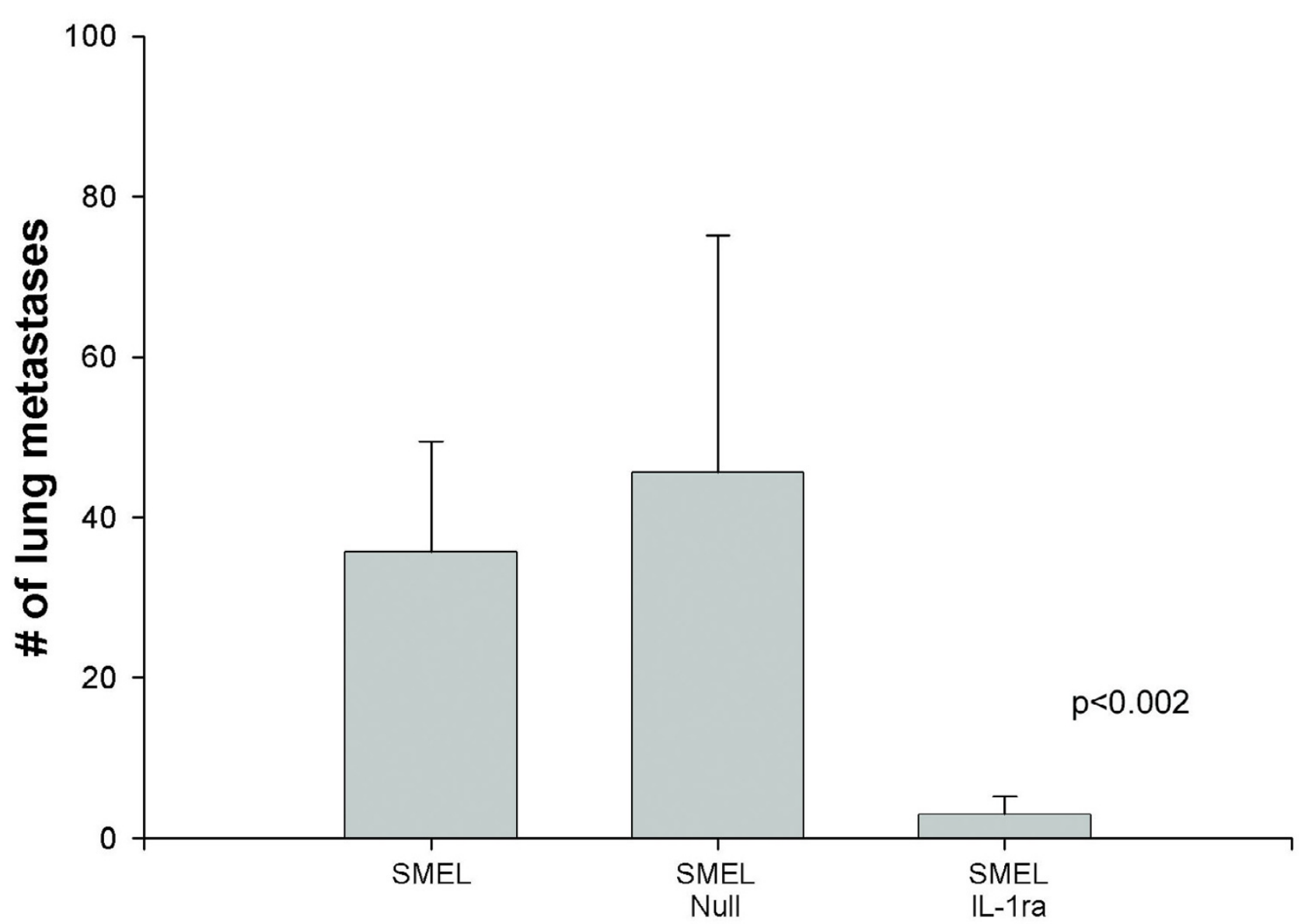

Figure 4

Inhibition of lung metastases in IL- I ra over-expressing melanoma xenografts. There was marked inhibition of lung metastases from the SMEL/IL-I ra cells compared with the null-transduced and wild-type controls. Cells were injected via tail vein, and the lungs were harvested 28 days later.

ble IL-1RII (sIL-1RII) form naturally occurs in the synovial fluid and plasma of healthy human subjects [32,33]. A negative correlation between sIL-1RII protein concentrations and presence of chronic arthritis in patients was noted by Jouvenne et al in which decreased sIL-1RII pro- tein concentrations were observed in patients with chronic arthritis [34]. These data implicate the potential anti-inflammatory effects of the soluble type II receptor. Other studies provided further evidence of the inhibitory role of sIL-1RII in the signaling and transduction of IL-1.

Table 2: Established anti-tumor activities of IL-I blocking methods and/or therapies based on published literature.

\begin{tabular}{|c|c|c|}
\hline Study & Year & Observation \\
\hline Voronov et al [7] & 2003 & $\begin{array}{l}\text { IL-I KO mice failed to develop solid tumors post injection of melanoma cells and exhibited significantly improved } \\
\text { survival compared with wild type animals. }\end{array}$ \\
\hline Saijo et al [19] & 2002 & Overexpression of IL-I is associated with an aggressive/malignant phenotype. \\
\hline Sawai et al [22] & 2003 & Same observation as above \\
\hline Voronov et al [7] & 2003 & Same observation as above \\
\hline Weinreich et al [28] & 2003 & IL-I ra-transduced xenografts exhibited decreased tumor growth and metastases in murine models. \\
\hline Elaraj et al [15] & 2006 & $\begin{array}{l}\text { Exogenously administered IL-I ra (anakinra) decreased tumor proliferation rate, metastases, and IL-8 and VEGF } \\
\text { mRNA expression of xenografts in murine models. }\end{array}$ \\
\hline
\end{tabular}


IL-1 Non-producing

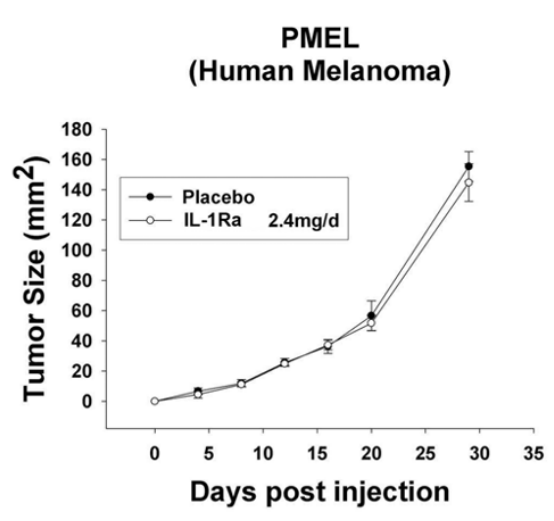

SL-2 (Human Squamous Cell Carcinoma)

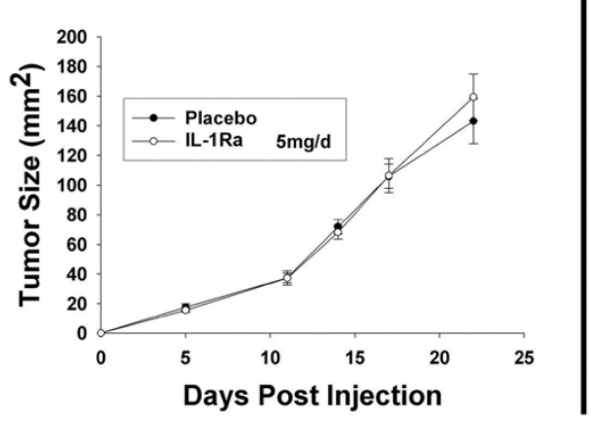

IL-1 Producing

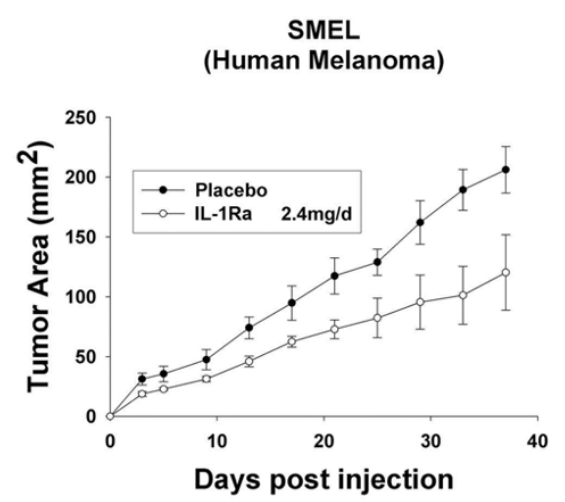

WIDR

(Human Colon Adenocarcinoma

(Human Lung Adenocarcinoma)

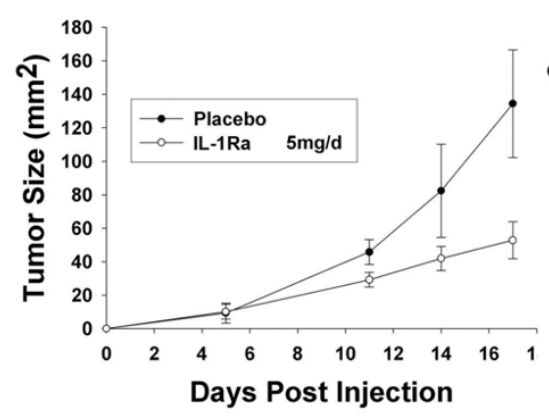

Figure 5

Partial tumor growth inhibition in IL-I but not non-IL-I producing xenografts treated with systemic IL-I ra protein. Two times $10^{6}$ tumor cells were injected s.c. into the flanks of athymic nude mice. On the day of tumor injection, s.c. IL-I ra therapy at various doses or placebo began and was administered daily into the opposite flank from tumor injection. ILI ra consistently resulted in a statistically significant decrease in growth rate of all three IL-I-producing tumors tested but had no effect on two non-IL-I-producing tumors.

Both in vitro and in vivo studies demonstrated that IL-1RIItransduced cells failed to respond to IL-1 [35,36]. Bessis et al used a collagen-induced arthritis murine model synonymous to human inflammatory arthritis to demonstrate the anti-inflammatory properties of sIL-1 RtII. Human sIL1RII-transfected keratinocytes engrated into arthritic mice decreased clinical and histological arthritis characteristics and decreased IL-6 and myeloperoixdase mRNA expression within the joints [37].

Although the IL-1RII is not responsible for IL-1 signal transduction, it does recruit the IL-1R accessory protein (IL-1RAcP) upon binding to IL-1. As previously discussed, IL-1RAcP is a necessary component for signal transduc- tion of IL-1. The IL-1 neutralizing effects of sIL-1RII then, are twofold; it sequesters IL-1RAcP, preventing its interaction with the IL-1RI and IL-1 complex, and it acts as a decoy by binding IL-1 and preventing its binding to the signal transducing IL-1RI $[12,38]$. These complementary inhibitory mechanisms enhance the IL-1 blocking effects of sIL-1RII. Additionally, sIL-1RII has increased the IL-1 blocking effects of IL-1ra, and studies cite evidence that sIL-1RII and IL-1ra interact synergistically to block IL-1 activity $[39,40]$. Burger et al found that sIL-1RII and IL-1ra administered simultaneously to human keratinocytes in vitro resulted in decreased production of prostaglandin $\mathrm{E}_{2}$ and metalloproteinases compared with either one treatment alone [40]. Based on such studies, combined novel 
therapeutics may be more effective in blocking the deleterious effects of IL-1 than individual treatments.

\section{Interleukin-I $\beta$-converting enzyme (ICE) inhibitors}

IL-1 $\beta$-converting enzyme (ICE), also known as caspase-1, is a protease necessary in the conversion of inactive IL-1 $\beta$ to the mature pro-inflammatory form and recently has been investigated as a novel therapeutic agent with IL-1 $\beta$ blocking potential. Additionally, ICE is responsible for the conversion of the pro-IL-18 form to its mature active form. Thus the advantages of employing ICE inhibitors are twofold: they diminish the actions of inflammatory cytokines IL-1 and IL-18 [41]. Due to the oral availability of ICE inhibitors, they are advantageous compared with injectable protein products such as IL-1ra. Patients prefer oral medications over injected ones, and orally administered drugs may result in better compliance and reduced cost [42]. The safety of ICE inhibitors remains under surveillance, and animal studies suggest this therapeutic is well-tolerated. Such studies found that genetically ICEdeficient mice did not appear to be at increased risk of developing infection or malignancies $[43,44]$. Furthermore, Rudolphi et al report that pralnacasan, the first orally bioavailable ICE inhibitor tested in humans, was well-tolerated in healthy subjects in a phase I/IIa clinical trial [45]. The effectiveness of pralnacasan was also investigated by Rudolphi et al in two osteoarthritis murine models where pralnacasan significantly decreased histopathological joint cartilage destruction. A phase II clinical trial involving pralnacasan for the management of osteoarthritis is underway [45]. ICE inhibiting agents such as pralnacasan and the more recent VX-765 demonstrate promise as anti-inflammatory therapeutics in that they are orally available and they elicit the anti-inflammatory response via the inhibition of the activities of both IL-1 and IL-18.

\section{Cytokine traps}

As discussed previously, IL-1 first binds to the IL-1RI, then recruits a second binding protein, the IL-1RAcP. IL-1 binds more avidly to this complex than the individual receptor, which is the basis upon which cytokine traps were founded [46]. Cytokine traps are produced by eukaryotic cells in culture and are soluble recombinant proteins consisting of cytokine cell-surface receptor domains bound inline to the Fc portion of human IgG1. These dimeric molecules avidly bind the cytokine of interest and have been developed for TNF $\alpha$, IL-4, IL-6, and IL1 [46]. Both in vitro and in vivo studies by Economides et al determined that the IL-1 trap more effectively blocked IL-1 and its effects than did IL-1ra. In vitro experiments measured the relative efficacies $\left(\mathrm{IC}_{50}\right)$ of the IL-trap and IL-1ra; in the presence of IL- $1 \beta$ ( 4 pM), the IC $_{50}$ of IL- 1 trap versus IL-1ra were $2 \mathrm{pM}$ and $70 \mathrm{pM}$, respectively [46]. Additionally, the IL- 1 trap avidly bound to IL- $1 \alpha$ as well as IL-1 $\beta$, an advantage over monoclonal antibodies against a single form of IL-1. In vivo studies found that IL1 traps injected subcutaneously into mice $24 \mathrm{~h}$ prior to injection with IL-1 $\beta$ resulted in complete inhibition of IL6 production, a cytokine induced by IL-1. This single dose also blocked the effects of a subsequent IL-1 $\beta$ injection 24 hours later, thus highlighting the ability of the IL-1 trap to exert its blocking activities over a prolonged amount of time. In contrast, IL-1 ra did not inhibit the activities of IL1 when administered at a dose 15-fold greater than the IL1 trap dose [46].

To date, this study has demonstrated that the IL- 1 trap has more successfully inhibited IL-1 activity than any other published study involving IL-1 blocking therapies, and based on entropy principles, it has been suggested that the IL-1 trap may bind IL-1 more avidly than even the IL-1RI itself [46]. Additionally, the ability of IL-1 traps to bind multiple cytokines such as IL- $1 \alpha$ and IL- $1 \beta$, coupled with its prolonged half life in vivo render it a rapidly emerging novel therapeutic agent in the inhibition of IL-1 activity. Results of a completed phase II study involving the treatment of 200 patients with weekly subcutaneous doses of IL-1 trap have been reported [31]. In this clinical trial, IL1 traps appeared to be safe, well-tolerated, and elicited no abnormal clinical laboratory values or evidence of increased number of infections, thus supporting further investigations of this protein.

\section{Conclusion}

Elevated IL-1 concentrations have been identified in numerous types of solid tumors in which the prognoses is markedly worse. This pleiotropic cytokine promotes tumor proliferation, angiogenesis, and metastases via its autocrine and paracrine effects within the tumor itself as well as the microenvironment. Our recent studies highlight the potential beneficial effects of both constitutively produced and exogenously administered IL-1ra, while numerous other IL-1 blocking therapeutics including antiIL-1 monoclonal antibodies, soluble IL-1RII, ICE inhibitors, and IL-1 cytokine traps have shown promise in the treatment of rheumatoid arthritis. The goal is to apply such novel treatments either alone or in conjunction with more traditional approaches towards the inhibition of IL1 in the treatment of cancer.

\section{Competing interests}

The author(s) declare that they have no competing interests.

\section{Authors' contributions}

AML drafted and edited the manuscript. SV participated in data collection and analysis and edited the manuscript. HX participated in data collection and analysis. HRA con- 
ceived the study design and helped draft and edit the manuscript. All authors read and approved the manuscript.

\section{Acknowledgements}

SV, HX, and HRA were supported in part by the funds from the Center for Cancer Research, National Cancer Institute, NIH, Bethesda, Maryland. AML was supported by the Howard Hughes Medical Institute-National Institutes of Health Research Scholars Program, Chevy Chase, Maryland.

\section{References}

I. Kuper H, Adami HO, Trichopoulos D: Infections as a major preventable cause of human cancer. J Intern Med 2000, 248: $|7|-183$.

2. Balkwill F, Mantovani A: Inflammation and cancer: back to Virchow? Lancet 200I, 357:539-545.

3. Mantovani A, Muzio M, Garlanda C, Sozzani S, Allavena P: Macrophage control of inflammation: negative pathways of regulation of inflammatory cytokines. Novartis Found Symp 2001, 234: |20-3 I; discussion |3 |-5.: |20-|3|.

4. Burke F, Relf M, Negus R, Balkwill F: A cytokine profile of normal and malignant ovary. Cytokine 1996, 8:578-585.

5. Komori A, Yatsunami J, Suganuma M, Okabe S, Abe S, Sakai A, Sasaki $\mathrm{K}$, Fujiki $\mathrm{H}$ : Tumor necrosis factor acts as a tumor promoter in BALB/3T3 cell transformation. Cancer Res 1993, 53:1982-1985.

6. Apte RN, Krelin Y, Song X, Dotan S, Recih E, Elkabets M, Carmi Y, Dvorkin T, White RM, Gayvoronsky L, Segal S, Voronov E: Effects of micro-environment- and malignant cell-derived interleukin$I$ in carcinogenesis, tumour invasiveness and tumour-host interactions. Eur J Cancer 2006, 42:75I-759.

7. Voronov E, Shouval DS, Krelin Y, Cagnano E, Benharroch D, Iwakura $Y$, Dinarello CA, Apte RN: IL-I is required for tumor invasiveness and angiogenesis. Proc Natl Acad Sci U S A 2003, 100:2645-2650.

8. Dinarello CA: Interleukin-I and interleukin-I antagonism. Blood 1991, 77:1627-1652.

9. Dinarello CA: Biologic basis for interleukin-I in disease. Blood 1996, 87:2095-2।47.

10. Endres S, Cannon JG, Ghorbani R, Dempsey RA, Sisson SD, Lonnemann G, Van der Meer JW, Wolff SM, Dinarello CA: In vitro production of IL I beta, IL I alpha, TNF and IL2 in healthy subjects: distribution, effect of cyclooxygenase inhibition and evidence of independent gene regulation. Eur J Immunol 1989, 1 9:2327-2333.

II. Cullinan EB, Kwee L, Nunes P, Shuster DJ, Ju G, Mclntyre KW, Chizzonite RA, Labow MA: IL-I receptor accessory protein is an essential component of the IL-I receptor. J Immunol 1998, | 6 I:5614-5620.

12. Mantovani A, Locati M, Vecchi A, Sozzani S, Allavena P: Decoy receptors: a strategy to regulate inflammatory cytokines and chemokines. Trends Immunol 200I, 22:328-336.

13. Dinarello CA, Wolff SM: The role of interleukin-I in disease. $N$ Engl J Med 1993, 328:106-II3.

14. Portier M, Zhang XG, Ursule E, Lees D, Jourdan M, Bataille R, Klein $\mathrm{B}$ : Cytokine gene expression in human multiple myeloma. $\mathrm{Br}$ J Haematol 1993, 85:5|4-520.

15. Elaraj DM, Weinreich DM, Varghese S, Puhlmann M, Hewitt SM, Carroll NM, Feldman ED, Turner EM, Alexander HR: The role of interleukin $I$ in growth and metastasis of human cancer xenografts. Clin Cancer Res 2006, I 2:1088-1096.

16. Chen Z, Malhotra PS, Thomas GR, Ondrey FG, Duffey DC, Smith CW, Enamorado I, Yeh NT, Kroog GS, Rudy S, McCullagh L, Mousa S, Quezado M, Herscher LL, Van Waes C: Expression of proinflammatory and proangiogenic cytokines in patients with head and neck cancer. Clin Cancer Res 1999, 5:1369-I379.

17. Gemma A, Takenaka K, Hosoya Y, Matuda K, Seike M, Kurimoto F, Ono Y, Uematsu K, Takeda Y, Hibino S, Yoshimura A, Shibuya M, Kudoh S: Altered expression of several genes in highly metastatic subpopulations of a human pulmonary adenocarcinoma cell line. Eur J Cancer 200I, 37: I554-I56I.

18. Apte RN, Voronov E: Interleukin-I--a major pleiotropic cytokine in tumor-host interactions. Semin Cancer Biol 2002, I 2:277-290.
19. Konishi N, Miki C, Yoshida T, Tanaka K, Toiyama Y, Kusunoki M: Interleukin-I receptor antagonist inhibits the expression of vascular endothelial growth factor in colorectal carcinoma. Oncology 2005, 68: |38-|45.

20. Barille S, Akhoundi C, Collette M, Mellerin MP, Rapp MJ, Harousseau $\mathrm{JL}$, Bataille R, Amiot M: Metalloproteinases in multiple myeloma: production of matrix metalloproteinase-9 (MMP-9), activation of proMMP-2, and induction of MMP-I by myeloma cells. Blood 1997, 90: I649-I655.

21. Akagi Y, Liu W, Xie K, Zebrowski B, Shaheen RM, Ellis LM: Regulation of vascular endothelial growth factor expression in human colon cancer by interleukin-Ibeta. Br J Cancer 1999, 80: I506- I5II.

22. Sawai H, Funahashi H, Yamamoto M, Okada Y, Hayakawa T, Tanaka $M$, Takeyama H, Manabe T: Interleukin- I alpha enhances integrin alpha(6)beta(I) expression and metastatic capability of human pancreatic cancer. Oncology 2003, 65:167-173.

23. Nozaki S, Sledge GWJ, Nakshatri H: Cancer cell-derived interleukin I alpha contributes to autocrine and paracrine induction of pro-metastatic genes in breast cancer. Biochem Biophys Res Commun 2000, 275:60-62.

24. Saijo Y, Tanaka M, Miki M, Usui K, Suzuki T, Maemondo M, Hong X, Tazawa R, Kikuchi T, Matsushima K, Nukiwa T: Proinflammatory cytokine IL-I beta promotes tumor growth of Lewis lung carcinoma by induction of angiogenic factors: in vivo analysis of tumor-stromal interaction. J Immunol 2002, I 69:469-475.

25. Ohlsson K, Bjork P, Bergenfeldt M, Hageman R, Thompson RC: Interleukin-I receptor antagonist reduces mortality from endotoxin shock. Nature 1990, 348:550-552.

26. Cominelli F, Nast CC, Clark BD, Schindler R, Lierena R, Eysselein VE, Thompson RC, Dinarello CA: Interleukin-I (IL-I) gene expression, synthesis, and effect of specific IL-I receptor blockade in rabbit immune complex colitis. J Clin Invest 1990, 86:972-980.

27. Rambaldi A, Torcia M, Bettoni S, Vannier E, Barbui T, Shaw AR, Dinarello CA, Cozzolino F: Modulation of cell proliferation and cytokine production in acute myeloblastic leukemia by interleukin-I receptor antagonist and lack of its expression by leukemic cells. Blood 1991, 78:3248-3253.

28. Weinreich DM, Elaraj DM, Puhlmann M, Hewitt SM, Carroll NM, Feldman ED, Turner EM, Spiess PJ, Alexander HR: Effect of Interleukin I Receptor Antagonist Gene Transduction on Human Melanoma Xenografts in Nude Mice. Cancer Res 2003, 63:5957-5961.

29. Schraufstatter IU, Chung J, Burger M: IL-8 activates endothelial cell CXCRI and CXCR2 through Rho and Rac signaling pathways. Am J Physiol Lung Cell Mol Physiol 200I, 280:L I 094-LI I03.

30. Neidhart M, Gay RE, Gay S: Anti-interleukin-I and anti-CD44 interventions producing significant inhibition of cartilage destruction in an in vitro model of cartilage invasion by rheumatoid arthritis synovial fibroblasts. Arthritis Rheum 2000, 43: $1719-1728$.

3I. Braddock M, Quinn A: Targeting IL-I in inflammatory disease: new opportunities for therapeutic intervention. Nat Rev Drug Discov 2004, 3:330-339.

32. Eastgate JA, Symons JA, Duff GW: Identification of an interleukin-I beta binding protein in human plasma. FEBS Lett 1990, 260:213-216.

33. Symons JA, Eastgate JA, Duff GW: A soluble binding protein specific for interleukin I beta is produced by activated mononuclear cells. Cytokine 1990, 2:190-198.

34. Jouvenne P, Vannier E, Dinarello CA, Miossec P: Elevated levels of soluble interleukin-I receptor type II and interleukin-I receptor antagonist in patients with chronic arthritis: correlations with markers of inflammation and joint destruction. Arthritis Rheum 1998, 41:1083-1089.

35. Re F, Sironi M, Muzio M, Matteucci C, Introna M, Orlando S, PentonRol G, Dower SK, Sims JE, Colotta F, Mantovani A: Inhibition of interleukin-I responsiveness by type II receptor gene transfer: a surface "receptor" with anti-interleukin-I function. J Exp Med 1996, I 83: 1841-1850.

36. Bossu P, Visconti U, Ruggiero P, Macchia G, Muda M, Bertini R, Bizzarri C, Colagrande A, Sabbatini V, Maurizi G, .: Transfected type II interleukin-I receptor impairs responsiveness of human keratinocytes to interleukin-I. Am J Pathol 1995, I47:1852-I86I. 
37. Bessis N, Guery L, Mantovani A, Vecchi A, Sims JE, Fradelizi D, Boissier MC: The type II decoy receptor of IL-I inhibits murine collagen-induced arthritis. Eur J Immunol 2000, 30:867-875.

38. Smith DE, Hanna R, Della F, Moore H, Chen H, Farese AM, MacVittie TJ, Virca GD, Sims JE: The soluble form of IL-I receptor accessory protein enhances the ability of soluble type II IL-I receptor to inhibit IL-I action. Immunity 2003, I 8:87-96.

39. Symons JA, Young PR, Duff GW: Soluble type II interleukin I (ILI) receptor binds and blocks processing of IL-I beta precursor and loses affinity for IL-I receptor antagonist. Proc Natl Acad Sci U S A 1995, 92:1714-1718.

40. Burger D, Chicheportiche R, Giri JG, Dayer JM: The inhibitory activity of human interleukin-I receptor antagonist is enhanced by type II interleukin-I soluble receptor and hindered by type I interleukin-I soluble receptor. J Clin Invest 1995, 96:38-4I.

4I. Naik SM, Cannon G, Burbach GJ, Singh SR, Swerlick RA, Wilcox JN, Ansel JC, Caughman SW: Human keratinocytes constitutively express interleukin- $I 8$ and secrete biologically active interleukin- 18 after treatment with pro-inflammatory mediators and dinitrochlorobenzene. J Invest Dermatol 1999, I I 3:766-772.

42. Randle JC, Harding MW, Ku G, Schonharting M, Kurrle R: ICE/Caspase-I inhibitors as novel anti-inflammatory drugs. Expert Opin Investig Drugs 200I, I 0: I 207-I 209.

43. Kuida K, Lippke JA, Ku G, Harding MW, Livingston DJ, Su MS, Flavell RA: Altered cytokine export and apoptosis in mice deficient in interleukin-I beta converting enzyme. Science 1995, 267:2000-2003.

44. Li P, Allen H, Banerjee S, Franklin S, Herzog L, Johnston C, McDowell J, Paskind M, Rodman L, Salfeld J, .: Mice deficient in IL-I beta-converting enzyme are defective in production of mature IL-I beta and resistant to endotoxic shock. Cell I995, 80:40I-4II.

45. Rudolphi K, Gerwin N, Verzijl N, van der KP, van den BW: Pralnacasan, an inhibitor of interleukin-Ibeta converting enzyme, reduces joint damage in two murine models of osteoarthritis. Osteoarthritis Cartilage 2003, I I:738-746.

46. Economides AN, Carpenter LR, Rudge JS, Wong V, Koehler-Stec EM, Hartnett C, Pyles EA, Xu X, Daly TJ, Young MR, Fandl JP, Lee F, Carver S, McNay J, Bailey K, Ramakanth S, Hutabarat R, Huang TT, Radziejewski C, Yancopoulos GD, Stahl N: Cytokine traps: multicomponent, high-affinity blockers of cytokine action. Nat Med 2003, 9:47-52.

\section{Publish with Biomed Central and every scientist can read your work free of charge}

"BioMed Central will be the most significant development for disseminating the results of biomedical research in our lifetime. "

Sir Paul Nurse, Cancer Research UK

Your research papers will be:

- available free of charge to the entire biomedical community

- peer reviewed and published immediately upon acceptance

- cited in PubMed and archived on PubMed Central

- yours - you keep the copyright

Submit your manuscript here:

http://www.biomedcentral.com/info/publishing_adv.asp
BioMedcentral 